\title{
Cell Type-Specific Interleukin-1 $\beta$ Signaling in the CNS
}

\author{
Deepak Srinivasan, ${ }^{1}$ Jui-Hung Yen, ${ }^{1}$ Donald J. Joseph, ${ }^{2}$ and Wilma Friedman ${ }^{1}$ \\ ${ }^{1}$ Department of Biological Sciences, Rutgers University, Newark, New Jersey 07102, and ${ }^{2}$ Center for Neurobiology and Behavior, Columbia University, New \\ York, New York 10032
}

Interleukin-1 $\beta(\mathrm{IL}-1 \beta)$ is a potent and pleiotropic inflammatory cytokine that is highly produced in the CNS under conditions of damage, disease, or stress. This cytokine acts on CNS glia to effect inflammatory responses, mediated in part via activation of the nuclear factor- $\kappa \mathrm{B}$ $(\mathrm{NF}-\kappa \mathrm{B})$ transcription factor, and consequent induction of numerous cytokines. Neurons as well as astrocytes in the hippocampus also express the type 1 IL-1 receptor, indicating that this cytokine can influence neuronal function directly, yet IL-1 $\beta$ does not induce production of cytokines in neurons as it does in glia. In contrast, IL-1 $\beta$ regulates synaptic function of hippocampal neurons. Here we demonstrate that different signaling pathways mediate IL-1 $\beta$ actions in neurons as compared with astrocytes. IL-1 $\beta$ activates the $\mathrm{p} 38$ mitogen-activated protein kinase (MAPK) signaling pathway and induces the activation of CREB in hippocampal neurons, in contrast to the activation of NF- $\kappa \mathrm{B}$ in hippocampal astrocytes, demonstrating cell type-specific signaling responses to IL-1 in the brain and yielding distinct functional responses.

Key words: interleukin-1; neurons; astrocytes; NF- $\kappa$ B; p38 MAPK; signal transduction

\section{Introduction}

Interleukin- $1 \beta$ (IL-1 $\beta$ ) is a proinflammatory cytokine that is highly produced by CNS glia under conditions of damage, stress, and disease. In the brain IL- $1 \beta$ elicits numerous diverse functional consequences. This cytokine acts on astrocytes and microglia to induce production of additional cytokines and growth factors, thereby promoting inflammatory activity in the brain (Benveniste, 1992; Merrill and Benveniste, 1996). In addition to mediating glial inflammatory functions (Dinarello, 1988), IL-1 acts as an endogenous pyrogen (Dascombe, 1985) and is a potent stimulator of the hypothalamic-pituitary-adrenal (HPA) axis (Berkenbosch et al., 1987; Sapolsky et al., 1987), thereby playing a major role in the physiological response to stress.

The ability of IL- $1 \beta$ to influence cellular function depends on expression of the appropriate receptor and activation of specific intracellular signaling pathways. Two receptors for IL-1 $\beta$ have been identified, but only the type 1 receptor (IL-1R1) is signal transducing (Colotta et al., 1993). The IL-1R1 is expressed on CNS glia (astrocytes and microglia), particularly after injury (Friedman, 2001), and also is expressed on specific populations of CNS neurons, including hippocampal pyramidal neurons (Yabuuchi et al., 1994; Ericsson et al., 1995; Friedman, 2001). IL-1 $\beta$ elicits distinct functional consequences in these different CNS cell types, regulating production of inflammatory cytokines in glia and influencing synaptic function of hippocampal neurons, resulting in modulation of long-term potentiation (LTP)

Received Dec. 26, 2003; revised June 7, 2004; accepted June 9, 2004.

This work was supported by the National Science Foundation. We thank Dr. Amy MacDermott (Columbia University) for expert advice on the calcium studies. We also thank Dr. Ron Hart (Rutgers University) for generously providing the recombinant rat IL-1 $\beta$ used in these studies and Jing-Yu Pan for excellent technical assistance.

Correspondence should be addressed to Dr. W. J. Friedman, Department of Biological Sciences, Rutgers University, 101 Warren Street, Newark, NJ 07102. E-mail: wilmaf@andromeda.rutgers.edu.

D01:10.1523/JNEUROSCI.5712-03.2004

Copyright $\odot 2004$ Society for Neuroscience $\quad$ 0270-6474/04/246482-07\$15.00/0
(Katsuki et al., 1990; Bellinger et al., 1993; Murray and Lynch, 1998; Kelly et al., 2001). In addition, IL- $1 \beta$ can increase tau phosphorylation and decrease synaptophysin expression in cortical neurons and may be an important mediator of $\beta$-amyloidinduced neurotoxicity (Li et al., 2003). Thus IL-1 $\beta$ has direct and distinct effects on neurons and glia in the brain.

The mechanisms governing the diverse actions of IL- $1 \beta$ in different cell types are not well understood. Many signaling pathways have been suggested to mediate IL-1 actions in different cell types. The most well characterized pathway involves a kinase cascade leading to activation of the nuclear factor $-\kappa \mathrm{B}(\mathrm{NF}-\kappa \mathrm{B})$ transcription factor (Croston et al., 1995; Cao et al., 1996; Malinin et al., 1997; Régnier et al., 1997). NF- $\kappa$ B activation in glia mediates the regulation of cytokines and growth factors by IL-1 (Sparacio et al., 1992; Friedman et al., 1996; Heese et al., 1998). However, other signal-transducing pathways also can be activated by IL- $1 \beta$, including the $\mathrm{p} 38$ and c-Jun $\mathrm{N}$-terminal kinase (JNK) mitogen-activated protein kinase (MAPK) pathways (O’Neill, 2002; Dunne and O'Neill, 2003). Activation of p38 has been suggested to regulate the effects of IL-1 $\beta$ on LTP in hippocampal neurons (Coogan et al., 1999) and on tau phosphorylation in cortical neurons ( $\mathrm{Li}$ et al., 2003). The specific pathway activated may differ in distinct cell types and may mediate the distinct biological consequences of IL- $1 \beta$ actions. In this study, we demonstrate that IL-1 activates distinct signaling pathways in hippocampal neurons as compared with astrocytes, which may govern the cell type-specific responses to this cytokine.

\section{Materials and Methods \\ Experimental animals}

Time-pregnant Sprague Dawley rats (Hilltop Lab, Scottsdale, PA) were housed in clear plastic cages with ad libitum access to food and water. Animals were kept on a $12 \mathrm{hr}$ light/dark cycle. Embryonic age was calculated from the day of discovery of the vaginal plug, which is embryonic day $1(\mathrm{E} 1)$. 


\section{Dissociated brain cultures}

On the appropriate day of embryonic development the pregnant animals were killed by exposure to $\mathrm{CO}_{2}$. Animals then were soaked in $80 \%$ ethanol for $10 \mathrm{~min}$. Fetuses were removed under sterile conditions and kept in PBS on ice for microscopic dissection of the hippocampus. The tissue was dissociated by trituration and plated on poly-L-lysine-coated $(0.1$ $\mathrm{mg} / \mathrm{ml}$ ) tissue culture flasks or wells.

Neuronal cultures. To grow neuronal cultures, we dissected, dissociated, and maintained E18 hippocampi in a serum-free environment (Friedman et al., 1993). Medium consisted of a 1:1 mixture of Eagle's MEM and Ham's F-12 supplemented with $6 \mathrm{mg} / \mathrm{ml}$ glucose, $25 \mu \mathrm{g} / \mathrm{ml}$ insulin, $60 \mu \mathrm{m}$ putrescine, $20 \mathrm{~nm}$ progesterone, $100 \mu \mathrm{g} / \mathrm{ml}$ transferrin, 30 nm selenium, $0.5 \mathrm{U} / \mathrm{ml}$ penicillin, and $0.5 \mu \mathrm{g} / \mathrm{ml}$ streptomycin. Dissociates grown in this medium contain $<2 \%$ glial cells after 1 week. Neurons were treated with cytokines on the last day of culture for the amounts of time indicated in each experiment. Optimal doses for recombinant rat IL- $1 \beta$ (generously provided by Dr. Ron Hart, Rutgers University, Piscataway, NJ) were determined from dose-response experiments and used at a final concentration of $10 \mathrm{ng} / \mathrm{ml}$.

Astrocyte cultures. Hippocampi from E21 rats were dissociated by trituration and grown on poly-L-lysine-coated flasks in Eagle's MEM with Earle's salts and $2 \mathrm{~mm}$ L-glutamine, $15 \%$ heat-inactivated fetal calf serum, $6 \mathrm{mg} / \mathrm{ml}$ glucose, $0.5 \mu \mathrm{g} / \mathrm{ml}$ penicillin, and $0.5 \mathrm{U} / \mathrm{ml}$ streptomycin. The astrocytes were grown to confluence. Glial subpopulations then were separated according to their differential adhesive properties (McCarthy and DeVellis, 1980). Flasks were shaken at $450 \mathrm{rpm}$ for $10 \mathrm{~min}$ to remove neurons and microglia, fresh medium was added, and the flasks were returned to the incubator for at least $2 \mathrm{hr}$. The flasks then were shaken overnight at $225 \mathrm{rpm}$ to remove type 2 astrocytes and oligodendrocytes. The confluent astrocytes were exposed to cytosine arabinoside $(0.1 \mathrm{~mm})$ for $3 \mathrm{~d}$ to eliminate any remaining non-astrocyte-contaminating populations. To ensure that no microglia remained to contaminate the astrocyte cultures, we treated some flasks with leucine methyl ester, a macrophage/microglial toxin (Simmons and Murphy, 1992). Finally, the astrocytes were trypsinized and replated at subconfluent density. Astrocytes were treated with cytokines on the last day of culture for the times indicated in each experiment.

\section{Electrophoretic mobility shift assays}

Nuclear extracts were prepared from control or IL- $1 \beta$-treated hippocampal neurons or astrocytes by a modification (Friedman et al., 1996) of the method of Dignam et al. (1983). Nuclear protein $(5 \mu \mathrm{g})$ was incubated with ${ }^{32} \mathrm{P}$-labeled oligonucleotides with the consensus sequences for either NF- $\kappa \mathrm{B}$ or cAMP response element (CRE). Competition with excess unlabeled oligonucleotides confirmed the specificity of the shifted bands. Supershift assays included specific antibodies to cAMP response element-binding protein (CREB; New England Biolabs, Beverly, MA) or activating transcription factor-2 (ATF-2; Santa Cruz Biotechnology, Santa Cruz, CA). DNA-protein complexes were resolved by electrophoresis via a $4.5 \%$ polyacrylamide gel under nonreducing conditions. Each gel is representative of at least three independent experiments.

\section{Western blot analysis}

Cultures were lysed in sample buffer containing $120 \mathrm{~mm}$ Tris, pH 6.8, 2\% SDS, and $10 \%$ glycerol. Proteins were quantified by using the Bradford assay (Bio-Rad, Hercules, CA). Equal amounts of protein were run on a $10 \%$ polyacrylamide gel and transferred electrophoretically to nitrocellulose. After transfer the membranes were stained with Ponceau $S$ to confirm equal loading and transfer of proteins in all samples. Filters were probed with antibodies to TRAF6 [tumor necrosis factor (TNF) receptor associated factor; kindly provided by Zhaodan Cao, Tularik, South San Francisco, CA], p65, c-fos (Santa Cruz Biotechnology), phospho-CREB (P-CREB), phospho-JNK (P-JNK), phospho-extracellular signalregulated protein kinase (P-ERK), or phospho-p38 (P-p38) antisera (Cell Signaling Technology, Beverly, MA) and were visualized by chemiluminescence. P-CREB, P-JNK, P-ERK, and P-p38 blots were stripped and reprobed with anti-CREB, anti-JNK, anti-ERK, and anti-p38 antisera (Cell Signaling Technology), respectively. Bands were evaluated densitometrically where indicated, using NIH Image software. Each blot is representative of at least three experiments.

\section{Immunostaining}

To visualize nuclear translocation of the NF- $\kappa \mathrm{B}$ subunits, we prepared hippocampal cultures from E18 embryos but maintained them in the presence of serum to allow for glial proliferation. Cultures were treated with IL- $1 \beta$ for $0.5,1$, or $4 \mathrm{hr}$, fixed with $4 \%$ paraformaldehyde, washed with PBS, blocked with PBS/0.3\% Triton X-100 and 5\% goat serum, and incubated overnight at $4^{\circ}$ with anti-p65 or anti-p50 antiserum $(1: 1000$; Santa Cruz Biotechnology). Labeled cells were visualized via the avidinbiotin method for peroxidase staining (ABC kit; Vector Laboratories, Burlingame, CA).

\section{Calcium imaging}

Dissociated hippocampal neurons were loaded with $5 \mu \mathrm{M}$ fura-2 AM (Molecular Probes, Eugene, OR) in HEPES buffer containing (in $\mathrm{mM}$ ) $145 \mathrm{NaCl}, 5 \mathrm{KCl}, 2 \mathrm{CaCl}_{2}, 10 \mathrm{HEPES}, 2 \mathrm{MgCl}_{2}$, and 5.5 glucose, $\mathrm{pH} 7.3$, at $325 \mathrm{mOsm}$ for $15-20 \mathrm{~min}$ at room temperature and then washed three times in the same buffer. A coverslip was placed in the perfusion chamber (400 $\mu$ l volume) and perfused with HEPES buffer at $2 \mathrm{ml} / \mathrm{min}$. Cells were viewed under an inverted microscope (Nikon, Tokyo, Japan). Background-subtracted intensity images at two excitation wavelengths ( 340 and $380 \mathrm{~nm}$ ) were acquired by using an intensified CCD camera and Axon Imaging Workbench 2.1 (Axon Instruments, Foster City, CA). The effects of NMDA or kainate (Tocris Cookson, Ellisville, MO), IL-1 $\beta$, and ATP (Sigma, St. Louis, MO) on intracellular calcium were examined sequentially. Each drug was diluted to final concentration in HEPES buffer and applied for 10-60 sec via bath perfusion; images were collected for 1-3 min. Traces are expressed as the ratio of fluorescence emission at 340 and $380 \mathrm{~nm}$, respectively. A calcium response was defined as two or more ratios in sequence that were at least $>5 \times$ the baseline ratio collected immediately before each drug application. All experiments were performed at room temperature.

\section{Results}

\section{Activation of NF- $\kappa$ B by IL-1 $\beta$ in hippocampal astrocytes, but not in neurons}

Many of the inflammatory actions of IL- $1 \beta$ are mediated by a signaling pathway involving a cascade of serine-threonine kinases, leading to activation of the NF- $\kappa \mathrm{B}$ transcription factor. We and others have shown previously that NF- $\kappa \mathrm{B}$ is activated by IL- $1 \beta$ in CNS astrocytes and mediates induction of growth factors and cytokines (Sparacio et al., 1992; Friedman et al., 1996). However, in contrast to astrocytes, no activation of NF- $\kappa \mathrm{B}$ was observed in cultured hippocampal neurons after exposure to IL-1 (Fig. 1A) despite the presence of the IL-1R1 on these cells (Friedman, 2001), suggesting that the cytokine may activate a distinct signaling pathway in different cell types in the brain. To confirm morphologically the different responses by neurons and astrocytes to IL- $1 \beta$ treatment, we exposed mixed neuron-glial cultures to IL- $1 \beta$ for $0.5,1$ or $4 \mathrm{hr}$, and we examined them for nuclear translocation of the $\mathrm{p} 65$ or $\mathrm{p} 50 \mathrm{NF}-\kappa \mathrm{B}$ subunit, which we have shown previously to be part of the complex activated in astrocytes (Friedman et al., 1996). Nuclear translocation of p65 was observed in astrocytes, but not in neurons in the same culture wells (Fig. $1 B$ ). Similar results were obtained when the cultures were stained for the p50 subunit (data not shown). Because the IL-1R1 is expressed in both hippocampal neurons and astrocytes (Friedman, 2001), the signaling pathways activated in these different cell types presumably diverge downstream of the receptor complex. We analyzed expression in neurons and astrocytes of TRAF6, a key adapter protein that couples the IL-1 receptor complex to the NF- $\kappa$ B pathway (Cao et al., 1996). TRAF6 was expressed abundantly in astrocytes, consistent with the activation of NF- $\kappa \mathrm{B}$ in these cells (Fig. 2). In contrast, TRAF6 expression was 
A
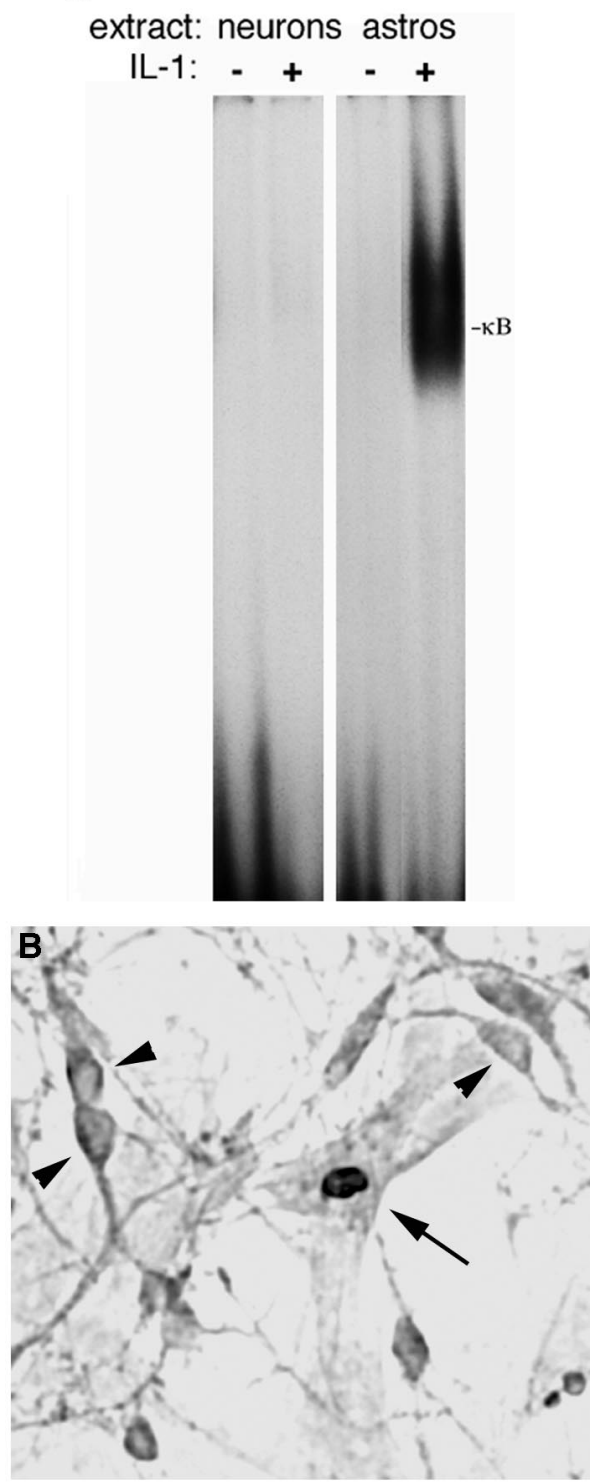

Figure 1. $\mathrm{IL}-1$ activates $\mathrm{NF}-\kappa \mathrm{B}$ in hippocampal astrocytes, but not in neurons. $A$, EMSA analysis of NF- $\kappa B$ binding in nuclear extracts from cultured hippocampal neurons and astrocytes. Nuclear extracts were prepared from cultures of hippocampal neurons or astrocytes that were untreated or treated with IL-1 $(10 \mathrm{ng} / \mathrm{ml})$ for $1 \mathrm{hr}$. Extracts were incubated with a labeled oligonucleotide probe consisting of the NF- $\kappa$ B binding sequence. IL-1 induced NF- $\kappa$ B binding in astrocytes, but not in neurons. $B$, Immunostaining of mixed neuron- glial cultures for the $p 65$ $\mathrm{NF}-\kappa \mathrm{B}$ subunit shows IL-1-induced nuclear translocation in astrocytes (arrow), but not in neurons (arrowheads).

not detected in the hippocampal neurons, which partially may account for the lack of NF- $\kappa$ B activation by IL- $1 \beta$ in these cells. Western blot analysis for the different NF- $\kappa$ B proteins demonstrated their presence (shown for p65; Fig. 2) in the hippocampal neurons despite the lack of activation by IL-1. Levels of expression of TRAF6 and p65 were unaffected by treatment with IL-1 in both neurons and astrocytes.

\section{IL-1 signaling in hippocampal neurons}

The IL-1R1 is expressed in these embryonic hippocampal neurons, yet IL- $1 \beta$ does not activate the NF- $\kappa$ B signaling pathway in these cells. To determine how IL- $1 \beta$ signals in these neurons, we treated cells with IL-1 and assessed them for activation of differ-
A

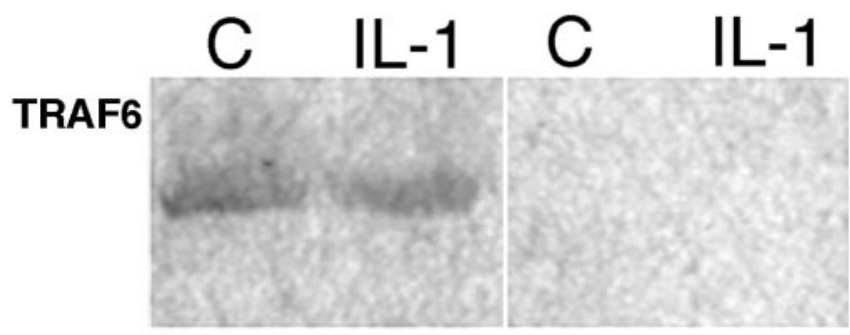

p65

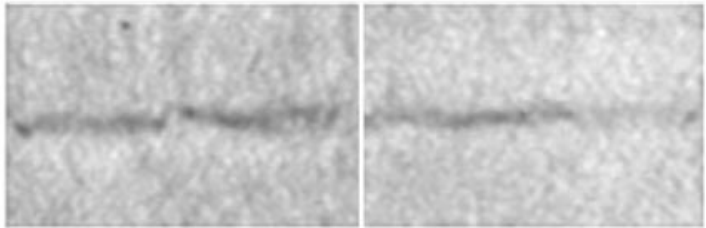

actin

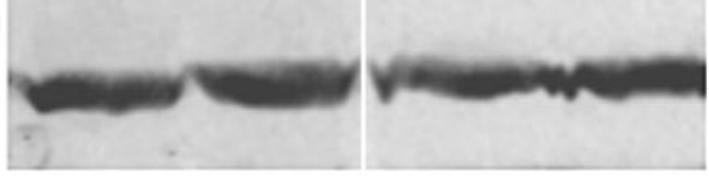

B

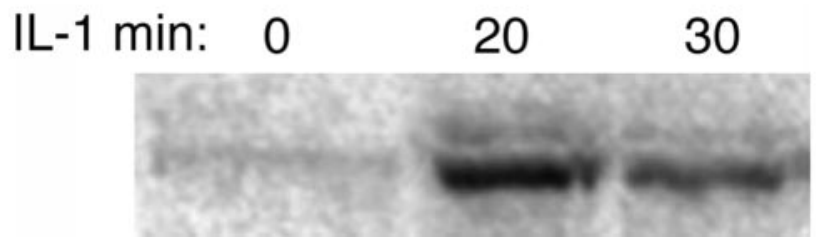

Figure 2. A, Western blot analysis of TRAF6 and p65 in hippocampal astrocytes and neurons. Cultured hippocampal neurons or astrocytes were untreated or treated with IL-1 for $1 \mathrm{hr}$. Equal amounts of protein were analyzed by Western blot for TRAF6 protein (top) or p65 (middle). The apparent decrease in p65 expression with IL-1 treatment was not observed consistently. Blots then were stripped and reprobed for actin (bottom). $B$, Western blot analysis of c-fos induction by IL-1 in hippocampal neurons. Cultured neurons were treated with IL-1 $(10 \mathrm{ng} / \mathrm{ml})$ for the indicated times. Lysates were analyzed by Western blot for c-fos.

ent signaling pathways that have been suggested to mediate IL-1 actions in different cell types. Many neurons have been shown to respond to IL-1 with an induction of c-fos (Ericsson et al., 1994). A time course of IL-1 $\beta$ treatment demonstrated that $c-f o s$ was induced by IL- $1 \beta$ in the cultured hippocampal neurons (Fig. $2 B$ ). We therefore investigated whether transcription factors known to regulate c-fos expression, such as CREB (Frank and Greenberg, 1994), were activated by IL-1 in hippocampal neurons. Nuclear extracts prepared from neuronal cultures showed binding to the CRE consensus oligonucleotide probe by electrophoretic mobility shift assay (EMSA) analysis. Nuclear CRE binding was elevated fivefold by IL-1 treatment (Fig. $3 A$ ). In contrast to the hippocampal neurons, astrocyte nuclear extracts showed no specific CRE binding.

The CRE consensus sequence can bind other transcription factors, such as ATF-2, in addition to CREB. Moreover, ATF-2 can be activated by JNK, a pathway that can be activated by IL-1 in some cell types (Kyriakis and Avruch, 1996). However, Western blot analysis of IL-1-treated neurons did not show any JNK phosphorylation (Fig. $4 B$ ), suggesting that this pathway was not activated by IL- $1 \beta$ in the hippocampal neurons. Consistent with this observation, supershift experiments with specific antibodies 
A

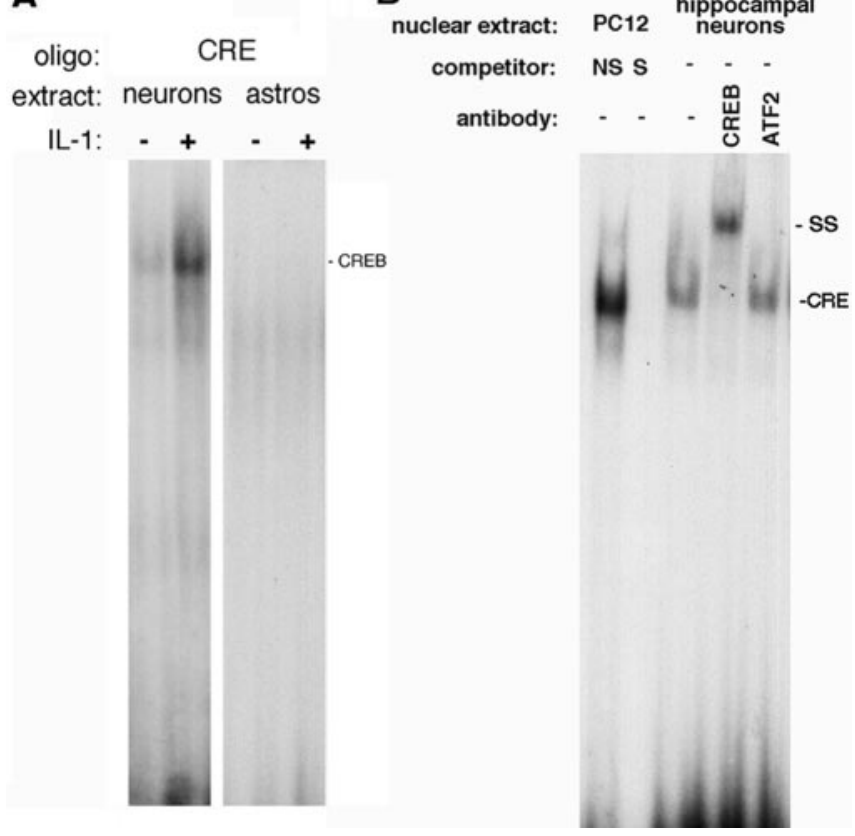

Figure 3. EMSA analysis of CREB binding in nuclear extracts from hippocampal neurons and astrocytes. A, Hippocampal neurons or astrocytes were untreated or treated with IL-1 (10 ng/ $\mathrm{ml}$ ) for $1 \mathrm{hr}$. EMSA analysis demonstrated binding to CRE in neurons, but not in astrocytes. $B$, Supershift assay. Nuclear extracts from IL-1-treated hippocampal neurons were incubated with the labeled CRE oligonucleotide and antibodies against CREB or ATF-2. Nuclear extracts from PC12 cells were used as control; competition with excess unlabeled nonspecific (NS) or specific (S) oligonucleotide probe demonstrates the specificity of the binding.

demonstrated that CREB itself, not ATF-2, was bound to the CRE oligonucleotide probe (Fig. 3B). To confirm that CREB was activated by IL- $1 \beta$ in these cells, we analyzed neuronal lysates by Western blot for CREB phosphorylation (Fig. 4A). Treatment with IL- $1 \beta$ induced CREB phosphorylation within $10 \mathrm{~min}$, was maximal at $20 \mathrm{~min}$, and declined thereafter.

CREB can be activated by numerous second messengers, including $\mathrm{Ca}^{2+}$ and cAMP, as well as by the ERK and p38 MAPK signaling pathways. In a previous study, we had shown that IL-1 did not elicit any change in cAMP levels in cultures of hippocampal neurons and glia (Friedman et al., 1992). To determine whether calcium signaling mediated CREB phosphorylation in hippocampal neurons, we monitored intracellular calcium by fura-2 imaging. Neurons initially were stimulated with NMDA or kainate to establish the calcium response and then treated with IL- $1 \beta$. No changes in calcium levels were detected in response to IL-1 treatment (Fig. 5). After the IL- $1 \beta$ was washed out, ATP was added to demonstrate that the neurons retained the ability to respond to an appropriate stimulus (Fig. $5 C$ ). Thus the activation of CREB by IL- $1 \beta$ did not appear to be mediated by $\mathrm{Ca}^{2+}$ signaling. To assess whether any of the MAPK signaling pathways mediated IL-1 activation of CREB, we performed Western blot analysis of IL-1-treated hippocampal neurons to determine phosphorylation of the different MAP kinases. This analysis showed that neither JNK nor $\mathrm{p} 42 / \mathrm{p} 44$ MAPK (ERK) was phosphorylated by IL- $1 \beta$ treatment (Fig. $4 B, C$ ). However, treatment of hippocampal neurons with IL-1 $\beta$ induced phosphorylation of p38 MAPK within $5 \mathrm{~min}$, which was maximal after $20 \mathrm{~min}$ of treatment and declined thereafter (Fig. 4D). Pretreatment of the neurons with an inhibitor of p38 MAPK (SB203580; $10 \mu \mathrm{M}$ ) decreased phosphorylation of p38 (Fig. $6 \mathrm{~A}$ ) and attenuated phosphorylation of CREB (Fig. $6 \mathrm{~B}$ ), suggesting that activation of
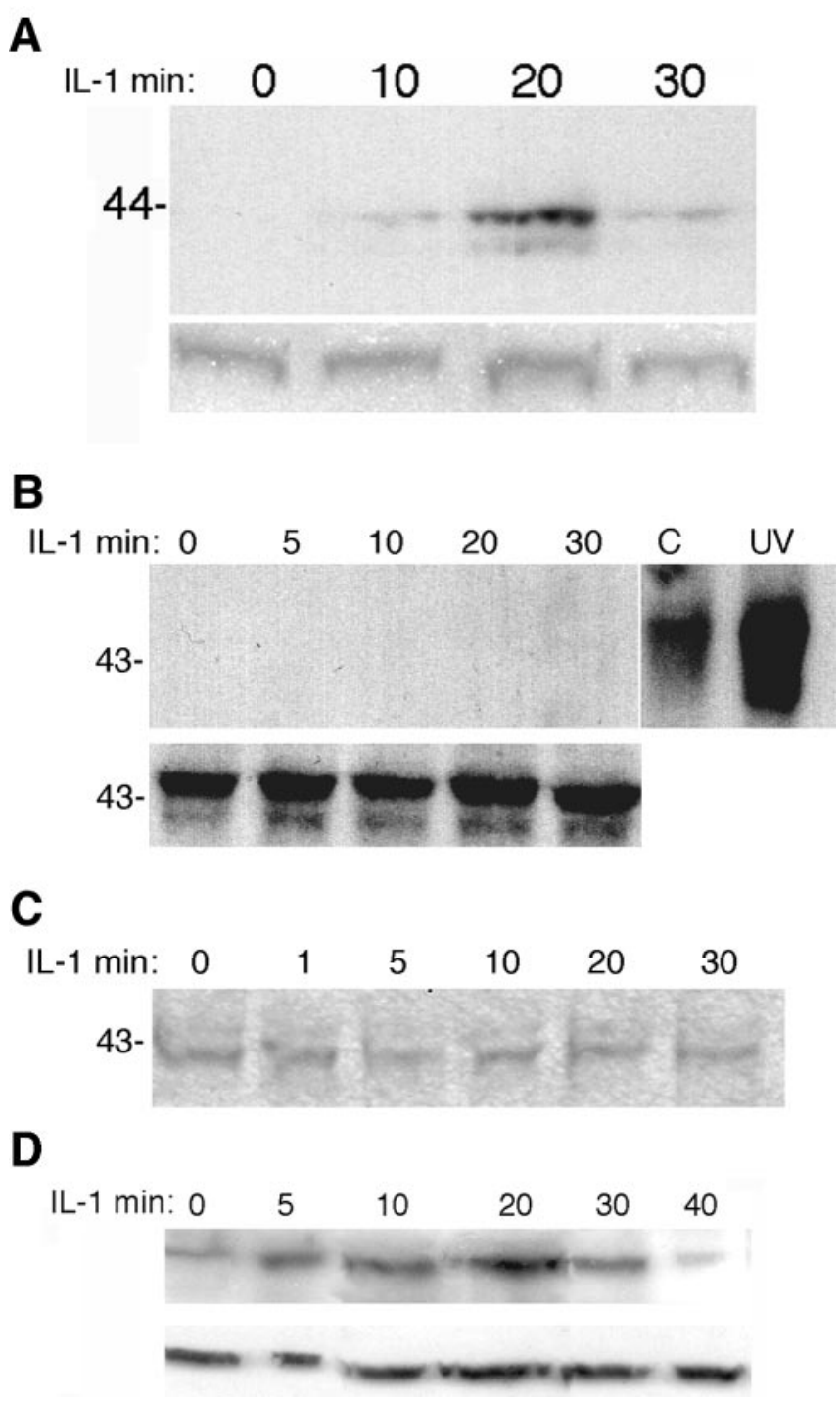

Figure 4. Western blot analysis for phosphorylation of CREB and the different MAP kinases in hippocampal neurons. Cultured hippocampal neurons were treated with IL-1 $\beta(10 \mathrm{ng} / \mathrm{ml})$ for the indicated times, lysed, and analyzed by Western blot for P-CREB $(A), P-\operatorname{JNK}(B), \mathrm{P}$-ERK ( $C$, or P-p38 (D). Blots were stripped and reprobed for total CREB $(A)$, JNK ( $B)$, and p38 (D) or ERK (data not shown because no differences in P-ERK were seen).

CREB by IL- $1 \beta$ in hippocampal neurons is mediated at least partially by $\mathrm{p} 38 \mathrm{MAPK}$.

\section{Discussion}

Interleukin-1 is a pleiotropic cytokine that influences numerous cell types. The most well characterized actions of IL-1 involve mediating inflammatory functions in lymphocytes, macrophages, and glial cells. These actions involve induction of cytokines, many of which are regulated by NF- $\kappa \mathrm{B}$ transcriptional activity. However, IL-1 receptors are present on different cell types not involved in mediating inflammatory activity. In particular, hippocampal neurons express the IL-1R1 and respond to this cytokine by modulating LTP. We have demonstrated in this study that IL- $1 \beta$ activates a signaling pathway in hippocampal neurons leading to activation of $\mathrm{p} 38$ and CREB, which may mediate effects on LTP, in contrast to the activation of NF- $\kappa$ B in astrocytes, which mediates induction of cytokines and growth factors. 
A

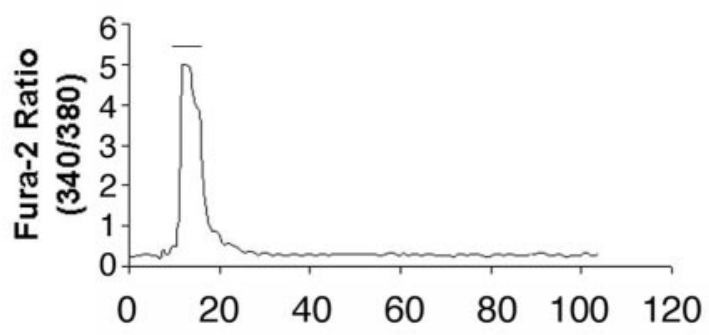

B

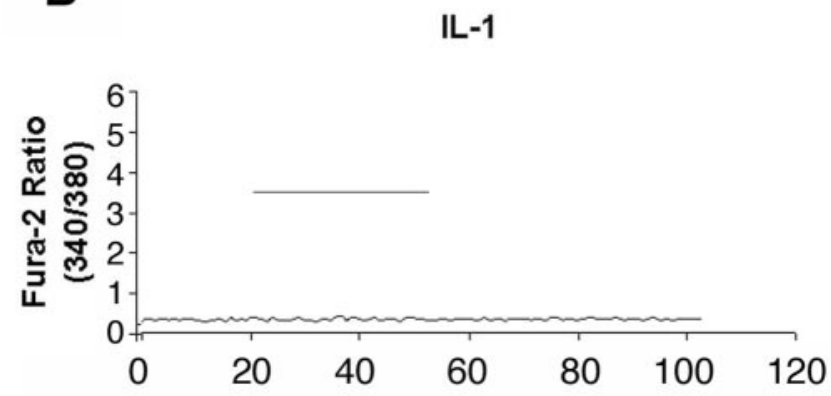

C

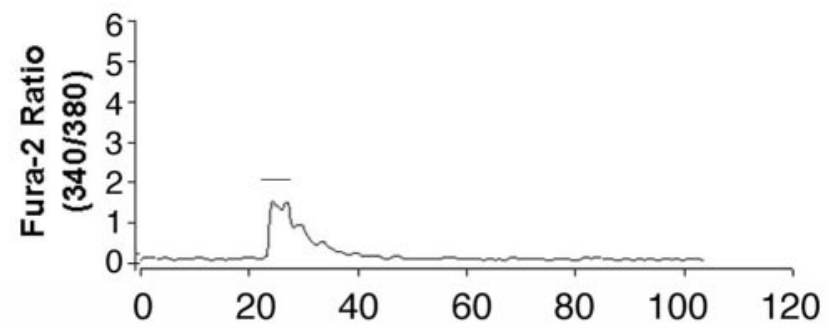

Time (sec)

Figure 5. Fura-2 analysis of intracellular calcium. $A$, Representative traces of kainateinduced $(100 \mu \mathrm{M})$ calcium responses recorded from cultured hippocampal neurons; kainate (KA) or NMDA (30 $\mu \mathrm{M})$ was applied for $\sim 10 \mathrm{sec}$ (bars above traces), inducing pronounced increase in internal calcium as determined by increase from baseline ratio ( $25>$ baseline ratio; $n=15$ for KA and $n=20$ for NMDA). B, IL-1 applied for $>1$ min on cells that previously responded to KA or NMDA failed to induce significant changes from baseline ratios $(n=35)$. C, ATP $(30 \mu \mathrm{m})$ applied for 10 sec to cells that failed to respond to IL-1 displayed pronounced increase in internal calcium ( $20>$ baseline ratios; $n=35$ ).

\section{Activation of NF- $\kappa$ B by IL-1 $\beta$}

With its binding to IL-1, the type 1 IL-1 receptor forms a complex with the receptor accessory protein (IL-1RAcP) to facilitate downstream signaling (Greenfeder et al., 1995). One signaling pathway that has been elucidated for IL-1 involves activation of a receptor-associated serine-threonine kinase, IRAK (Croston et al., 1995; Cao et al., 1996), and interaction with the adapter protein TRAF6 (Cao et al., 1996). This interaction results in activation of additional serine-threonine kinases, leading eventually to I $\kappa$ B phosphorylation (Malinin et al., 1997; Mercurio et al., 1997; Régnier et al., 1997; Woronicz et al., 1997) and dissociation of the inhibitory complex, allowing NF- $\kappa \mathrm{B}$ to translocate to the nucleus. Activation of this transcription factor plays a key role in inflammation, leading to production of inflammatory molecules
A
C $\mathrm{C}+\mathrm{SB}$
IL-1
$\mathrm{IL}-1+\mathrm{SB}$
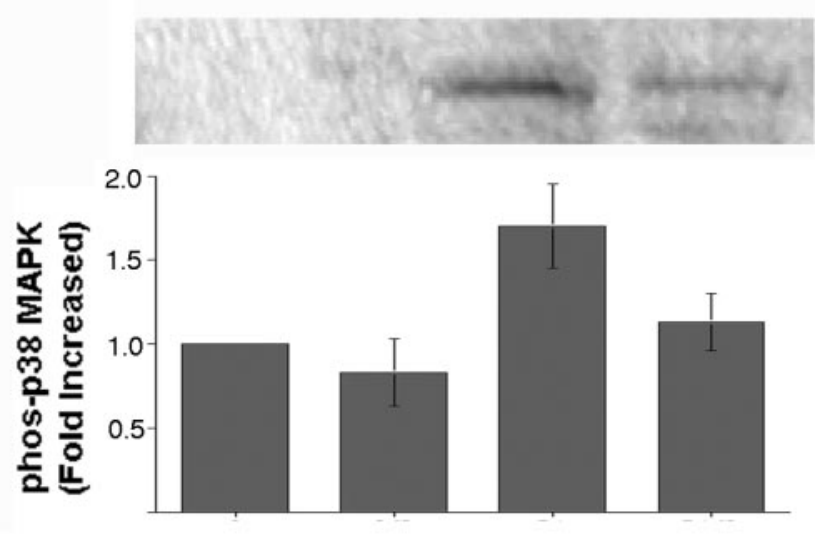

B
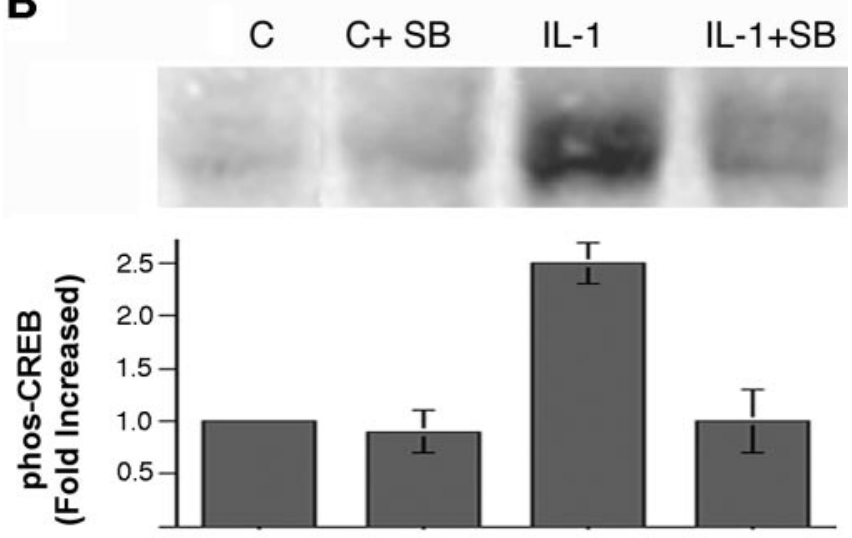

Figure 6. IL-1 signals via p38MAPKin hippocampal neurons. Cultured hippocampal neurons were treated for $10 \mathrm{~min}$ with the $\mathrm{p} 38$ inhibitor SB203580 $(10 \mu \mathrm{M})$ and then treated with vehicle or IL-1 (10 ng/ml) for $20 \mathrm{~min}$. The $\mathrm{p} 38$ inhibitor attenuated IL-1-induced phosphorylation of $\mathrm{p} 38$ $(A)$ and of $C R E B(B)$. The graphs show the combined data from three independent experiments. Error bars represent SEM.

such as IL-6 and MCP-1 as well as additional IL- 1 and TNF. The $\mathrm{NF}-\kappa \mathrm{B}$ transcription factor is activated by IL- $1 \beta$ in hippocampal astrocytes (Friedman et al., 1996), mediating production of cytokines and growth factors (Sparacio et al., 1992; Friedman et al., 1996), consistent with a role in CNS inflammation.

\section{IL-1 $\beta$ signaling in hippocampal neurons}

$\mathrm{NF}-\kappa \mathrm{B}$ has been shown to be constitutively active in some neuronal populations, including adult hippocampal neurons (Kaltschmidt et al., 1994). However, our current study indicates that embryonic hippocampal neurons, which express IL-1R1 (Friedman, 2001), do not respond to IL- $1 \beta$ treatment with activation of this transcription factor. It is unclear whether this represents a difference between embryonic and adult neurons or whether adult hippocampal neurons also would fail to regulate this transcription factor in response to IL- $1 \beta$ despite its constitutive activation in these cells. EMSA analysis revealed CRE binding in IL- $1 \beta$-treated neurons, but not in astrocytes, indicating differential signaling pathways activated by the cytokine in these different cell populations. Multiple signaling pathways have been suggested to mediate IL-1 actions in different cell types. In addition to the NF- $\kappa \mathrm{B}$ pathway, IL-1 has been shown to activate the JNK pathway, leading to activation of the ATF-2 transcription factor (Kyriakis and Avruch, 1996). Because ATF-2 also binds the 
CRE consensus sequence, it was critical to determine which transcription factor was bound to the CRE consensus sequence in the hippocampal neurons. Supershift experiments demonstrated that CREB, not ATF-2, was bound to the CRE sequence, and Western blot analysis showed that CREB was phosphorylated by IL- $1 \beta$ treatment of hippocampal neurons. Many signaling pathways have been shown to lead to activation of CREB (Shaywitz and Greenberg, 1999). Although in some cases cAMP/protein kinase A-mediated phosphorylation of CREB is sufficient to induce transcriptional activity, growth factors require activation of additional transcription factors, such as SRF, to induce expression of a target gene such as c-fos (Bonni et al., 1995). We observed that SRE as well as CRE binding was induced by IL-1 in hippocampal neurons, suggesting that IL-1 signaling in these neurons may resemble growth factor signaling in activating multiple transcription factors. However, the pathway mediating IL- $1 \beta$ activation of CREB was undefined. Previous studies had shown no activation of cAMP by IL- $1 \beta$ in these cells (Friedman et al., 1992), suggesting that this cytokine may activate CREB by a distinct signaling pathway. $\mathrm{Ca}^{2+}$ signaling also can lead to CREB activation; however, fura- 2 analysis of IL- $1 \beta$-treated hippocampal neurons revealed no change in calcium signaling. Additional signaling pathways that can lead to CREB phosphorylation include both the ERK and p38 MAPK pathways. Although treatment of the hippocampal neurons with IL-1 $\beta$ did not induce ERK phosphorylation, it did elicit p38 MAPK phosphorylation. Moreover, prevention of $\mathrm{p} 38$ phosphorylation attenuated phosphorylation of CREB, indicating that the $\mathrm{p} 38$ pathway is responsible at least partially for CREB activation by IL- $1 \beta$ in hippocampal neurons. These results are consistent with a recent study demonstrating IL-1 activation of p38 MAPK in cortical neurons (Li et al., 2003).

IL-1 had been shown to influence synaptic function of hippocampal neurons, with modulating effects on LTP (Katsuki et al., 1990; Bellinger et al., 1993; Murray and Lynch, 1998). Recent studies have shown that the effects of IL-1 on LTP were mediated by p38 MAPK (Coogan et al., 1999; Kelly et al., 2003). Our identification of CREB as a downstream mediator of IL-1 via p38 activation in hippocampal neurons may provide a mechanism by which IL-1 influences LTP in this neuronal population, because CREB is known to regulate expression of genes involved in hippocampal LTP and memory (Kaang et al., 1993; Frank and Greenberg, 1994). We suggest that IL-1, which is highly produced in the brain under conditions of damage, stress, and disease, has distinct effects on neurons and glia in the brain, which together characterize the response to stress. One consequence of IL- 1 is to promote inflammatory responses in glia via NF- $\kappa \mathrm{B}$ activation, and another is to influence directly the function of hippocampal neurons associated with memory by regulating CREB activity via p38 MAPK signaling. Thus the pleiotropic effects of IL-1 in the brain may serve to coordinate the neural response to stress or injury.

\section{References}

Bellinger FP, Madamba S, Siggins GR (1993) Interleukin-1 $\beta$ inhibits synaptic strength and long-term potentiation in the rat CA1 hippocampus. Brain Res 628:227-234.

Benveniste EN (1992) Cytokines: influence on glial cell gene expression and function. In: Neuroimmunoendocrinology, Ed 2 (Blalock JE, ed), pp 106-153. Basel: Karger.

Berkenbosch F, Van Oers J, Del Rey A, Tilders F, Besedovsky H (1987) Corticotropin-releasing factor-producing neurons in the rat activated by interleukin-1. Science 238:524-526.

Bonni A, Ginty DD, Dudek H, Greenberg ME (1995) Serine 133- phosphorylated CREB induces transcription via a cooperative mechanism that may confer specificity to neurotrophin signals. Mol Cell Neurosci 6:168-183.

Cao Z, Henzel WJ, Gao X (1996) IRAK: a kinase associated with the interleukin-1 receptor. Science 271:1128-1131.

Colotta F, Re F, Muzio M, Bertini R, Polentarutti N, Sironi M, Giri JG, Dower SK, Sims JE, Mantovani A (1993) Interleukin-1 type II receptor: a decoy target for IL-1 that is regulated by IL-4. Science 261:472-475.

Coogan AN, O’Neill LAJ, O'Connor JJ (1999) The p38 mitogen-activated protein kinase inhibitor SB203580 antagonizes the inhibitory effects of interleukin- $1 \beta$ on long-term potentiation in the rat dentate gyrus in vitro. Neuroscience 93:57-69.

Croston GE, Cao Z, Goeddel DV (1995) NF- $\kappa$ B activation by interleukin-1 (IL-1) requires an IL-1 receptor-associated protein kinase activity. J Biol Chem 270:16514-16517.

Dascombe MJ (1985) The pharmacology of fever. Prog Neurobiol 25:327-373. Dignam JD, Martin PL, Shastry BS, Roeder RF (1983) Eukaryotic gene transcription with purified components. Methods Enzymol 101:582-599.

Dinarello CA (1988) Biology of interleukin-1. FASEB J 2:108-115.

Dunne A, O'Neill L (2003) The interleukin-1 receptor/Toll-like receptor superfamily: signal transduction during inflammation and host defense. Sci STKE 171:re3.

Ericsson A, Kovacs KJ, Sawchenko PE (1994) A functional anatomical analysis of central pathways subserving the effects of interleukin-1 on stressrelated neuroendocrine neurons. J Neurosci 14:897-913.

Ericsson A, Liu C, Hart RP, Sawchenko PE (1995) Type 1 interleukin-1 receptor in the rat brain: distribution, regulation, and relationship to sites of IL-1 cellular activation. J Comp Neurol 361:681-698.

Frank DA, Greenberg ME (1994) CREB: a mediator of long-term memory from mollusks to mammals. Cell 79:5-8.

Friedman WJ (2001) Cytokines regulate expression of the type 1 interleukin-1 receptor in rat hippocampal neurons and glia. Exp Neurol 168:23-31.

Friedman WJ, Altiok N, Fredholm BB, Persson H (1992) Mechanisms of nerve growth factor mRNA regulation by interleukin- $1 \beta$ in hippocampal cultures: role of second messengers. J Neurosci Res 33:37-46.

Friedman WJ, Ibanez CF, Hallbook F, Persson H, Cain LD, Dreyfus CF, Black IB (1993) Differential actions of neurotrophins in the locus coeruleus and basal forebrain. Exp Neurol 119:72-78.

Friedman WJ, Thakur S, Seidman L, Rabson AB (1996) Regulation of nerve growth factor mRNA by interleukin-1 in rat hippocampal astrocytes is mediated by NF- $\kappa$ B. J Biol Chem 271:31115-31120.

Greenfeder SA, Nunes P, Kwee L, Labow M, Chizzonite RA, Ju G (1995) Molecular cloning and characterization of a second subunit of the interleukin-1 receptor complex. J Biol Chem 270:13757-13765.

Heese K, Hock C, Otten U (1998) Inflammatory signals induce neurotrophin expression in human microglial cells. J Neurochem 70:699-707.

Kaang BK, Kandel ER, Grant SG (1993) Activation of cAMP-responsive genes by stimuli that produce long-term facilitation in Aplysia sensory neurons. Neuron 10:427-435.

Kaltschmidt C, Kaltschmidt B, Neumann H, Wekerle H, Baeuerle PA (1994) Constitutive NF- $\kappa$ B activity in neurons. Mol Cell Biol 14:3981-3992.

Katsuki H, Nakai S, Hirai Y, Akaji K, Kiso Y, Satoh M (1990) Interleukin- $1 \beta$ inhibits long-term potentiation in the CA3 region of mouse hippocampal slices. Eur J Pharmacol 181:323-326.

Kelly A, Lynch A, Vereker E, Nolan Y, Queenan P, Whittaker E, O’Neill L, Lynch M (2001) The anti-inflammatory cytokine, interleukin (IL)-10, blocks the inhibitory effect of IL- $1 \beta$ on long-term potentiation. A role for JNK. J Biol Chem 276:45564-45572.

Kelly A, Vereker E, Nolan Y, Brady M, Barry C, Loscher C, Mills K, Lynch M (2003) Activation of p38 plays a pivotal role in the inhibitory effect of lipopolysaccharide and interleukin- $1 \beta$ on long-term potentiation in rat dentate gyrus. J Biol Chem 278:19453-19462.

Kyriakis JM, Avruch J (1996) Protein kinase cascades activated by stress and inflammatory cytokines. BioEssays 18:5-15.

Li Y, Liu L, Barger SW, Griffin WST (2003) Interleukin-1 mediates pathological effects of microglia on tau phosphorylation and on synaptophysin synthesis in cortical neurons through a p38-MAPK pathway. J Neurosci 23:1605-1611.

Malinin NL, Boldin MP, Kovalenko AV, Wallach D (1997) MAP3K-related kinase involved in NF- $\kappa$ B induction by TNF, CD95, and IL-1. Nature 385:540-544. 
McCarthy KD, DeVellis J (1980) Preparation of separate astroglial and oligodendroglial cell cultures from rat cerebral tissue. J Cell Biol 85:890-902.

Mercurio F, Zhu H, Murray BW, Shevchenko A, Bennett BL, Li JW, Young DB, Barbosa M, Mann M, Manning A, Rao A (1997) IKK-1 and IKK-2: cytokine-activated $\mathrm{I} \kappa \mathrm{B}$ kinases essential for NF- $\kappa \mathrm{B}$ activation. Science 278:860-866.

Merrill JE, Benveniste EN (1996) Cytokines in inflammatory brain lesions: helpful and harmful. Trends Neurosci 19:331-338.

Murray CA, Lynch MA (1998) Evidence that increased hippocampal expression of the cytokine interleukin- $1 \beta$ is a common trigger for age- and stressinduced impairments in long-term potentiation. J Neurosci 18:2974-2981.

O'Neill L (2002) Signal transduction pathways activated by the IL-1 receptor/Toll-like receptor superfamily. Curr Top Microbiol Immunol 270:47-61.

Régnier CH, Song HY, Gao X, Goeddel DV, Cao Z, Rothe M (1997) Identification and characterization of an I $\kappa$ B kinase. Cell 90:373-383.
Sapolsky R, Rivier C, Yamamoto G, Plotsky P, Vale W (1987) Interleukin-1 stimulates the secretion of hypothalamic corticotropin-releasing factor. Science 238:522-524.

Shaywitz AJ, Greenberg ME (1999) CREB: a stimulus-induced transcription factor activated by a diverse array of extracellular signals. Annu Rev Biochem 68:821-861.

Simmons ML, Murphy S (1992) Induction of nitric oxide synthase in glial cells. J Neurochem 59:897-905.

Sparacio SM, Zhang Y, Vilcek J, Benveniste EN (1992) Cytokine regulation of interleukin-6 gene expression in astrocytes involves activation of an NF- $\kappa$ B-like nuclear protein. J Neuroimmunol 39:231-242.

Woronicz JD, Gao X, Cao Z, Rothe M, Goeddel DV (1997) I $\kappa$ B kinase- $\beta$ : NF- $\kappa \mathrm{B}$ activation and complex formation with $\mathrm{I} \kappa \mathrm{B}$ kinase $\alpha$ and NIK Science 278:866-869.

Yabuuchi K, Minami M, Katsumata S, Satoh M (1994) Localization of type 1 interleukin-1 receptor mRNA in rat brain. Mol Brain Res 27:27-36. 